\title{
触 New Disease Reports \\ First report of Eggplant mottled dwarf virus causing flower breaking and vein clearing in Hydrangea macrophylla in Germany
}

W. Menzel ${ }^{1 *}$, S. Winter ${ }^{1}$ and J. Hamacher ${ }^{2}$

${ }^{1}$ Leibniz Institute, DSMZ-German Collection of Microorganisms and Cell Cultures, Plant Virus Department, Inhoffenstraße 7 B, 38124 Braunschweig, Germany; ${ }^{2}$ University of Bonn, Department of Phytomedicine, Institute of Crop Science and Resource Conservation, Nußallee 9, 53115 Bonn, Germany

*E-mail: wulf.menzel@dsmz.de

Received: 17 Aug 2016. Published: 14 Sep 2016. Keywords: EMDV

In May 2013, an unknown disease was observed in hydrangea (Hydrangea macrophylla) in a nursery in North Rhine-Westphalia, Germany. Symptoms observed consisted of flower breaking (Fig. 1) and vein clearing/banding (Fig. 2). Hydrangea, native to Japan, is a deciduous shrub which is mainly used in landscaping as bedding plant or at borders. Many cultivars are of economic importance mainly due to the decorative flowers.

Examination of leaf dip extracts by electron microscopy showed the presence of bullet-shaped and filamentous virions resembling those of rhabdoviruses and potexviruses, respectively. The potexvirus was identified as an isolate of Hydrangea ringspot virus (HdRSV), a virus commonly found in hydrangea. However, the symptoms observed were not previously associated with the presence of HdRSV, which usually causes ring- or chlorotic spots on leaves or remains symptomless. The putative rhabdovirus was mechanically transmitted to and maintained in Nicotiana benthamiana, showing leaf mottling and crinkling upon infection. Symptomatic hydrangea and $N$. benthamiana leaf material was tested by RT-PCR for the presence of rhabdoviruses using the degenerate primers Rhab $F$ (5'-GGATMTGGGGBCATCC-3') and Rhab R (5'-GTCCABCCYTTTTGYC-3') according to Dietzgen et al. (2013), which were designed to amplify a conserved part of the rhabdovirus $L$ gene. Amplicons of the expected size of $\sim 900 \mathrm{bp}$ were obtained and comparison with GenBank sequences revealed up to $99 \%$ aa $(97 \% \mathrm{nt})$ sequence identity to Eggplant mottled dwarf virus (EMDV; e.g. GenBank Accession Nos. HG916824 or HG916825), and thus identified the hydrangea isolate as an isolate of EMDV. The presence of EMDV in symptomatic leaf material was confirmed by a strong ELISA reaction with an EMDV-specific antiserum (DSMZ AS-0836), which was originally raised against a Moroccan tomato isolate. Electron microscopic investigations on embedded and ultrathin sectioned leaf material from $H$. macrophylla revealed rhabdovirus-like particles budding into perinuclear spaces (Fig. 3).

EMDV was first reported from eggplant in Italy in the 1960's and is endemic in the Mediterranean basin (Martelli, 2011). It is mainly found in solanaceaous vegetables but was also identified occasionally infecting ornamentals of the genera Hibiscus, Lonicera, Pelargonium and Pittosporum (Pappi et al., 2016). This is the first report of EMDV infecting $H$. macrophylla. Whether the observed symptoms are caused by EMDV alone or by synergistic effects with HdRSV remains unresolved. The EMDV isolate is available at the DSMZ plant virus collection under accession no. PV-1127 and the sequence was deposited in GenBank (KX709963).

\section{References}

Dietzgen RG, Tan ER, Yong AHS, 2013. Partial polymerase gene sequence, phylogeny and RT-PCR diagnostic assay for Datura yellow vein nucleorhabdovirus. Australasian Plant Disease Notes 8, 21-25. http://dx.doi.org/10.1007/s13314-012-0087-1

Martelli GP, Russo M, Rubino L, 2011. Eggplant mottled dwarf virus. Descriptions of Plant Viruses No. 421. Wellesbourne, UK: AAB. http://www.dpvweb.net/dpv/showadpv.php?dpvno=421\#host (Accessed 17 August 2016)

Pappi PG, Maliogka VI, Amoutzias GD, Katis NI, 2016. Genetic variation of eggplant mottled dwarf virus from annual and perennial plant hosts. Archives of Virology 161, 631-639.

http://dx.doi.org/10.1007/s00705-015-2705-7
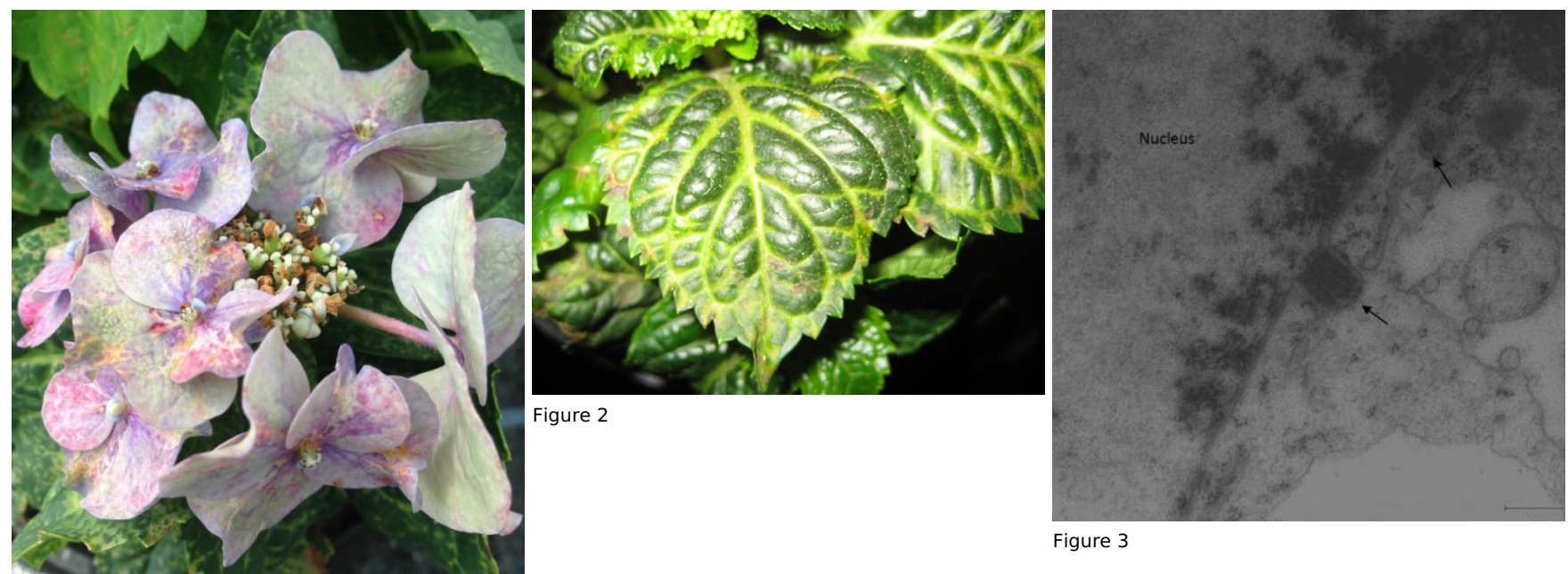

Figure 3

Figure 1

To cite this report: Menzel W, Winter S, Hamacher J, 2016. First report of Eggplant mottled dwarf virus causing flower breaking and vein clearing in Hydrangea macrophylla in Germany. New Disease Reports 34, 11. http://dx.doi.org/10.5197/j.2044-0588.2016.034.011 (c) 2016 The Authors This report was published on-line at www.ndrs.org.uk where high quality versions of the figures can be found. 